\title{
A Comparison of Direct and Iterated Multistep AR Methods for Forecasting Macroeconomic Time Series
}

\author{
Massimiliano Marcellino \\ Istituto di Economia Politica, Universita Bocconi and IGIER \\ James H. Stock \\ Department of Economics, Harvard University \\ and the NBER \\ and \\ Mark W. Watson* \\ Department of Economics and Woodrow Wilson School, Princeton University \\ and the NBER \\ February 2004 \\ (Revised April 2005)
}

*The authors thank Jin-Lung Lin, Frank Schorfheide, Ken West, and two referees for comments. This research was funded in part by NSF grant SBR-0214131. 


\begin{abstract}
"Iterated" multiperiod ahead time series forecasts are made using a one-period ahead model, iterated forward for the desired number of periods, whereas "direct" forecasts are made using a horizon-specific estimated model, where the dependent variable is the multi-period ahead value being forecasted. Which approach is better is an empirical matter: in theory, iterated forecasts are more efficient if the one-period ahead model is correctly specified, but direct forecasts are more robust to model misspecification. This paper compares empirical iterated and direct forecasts from linear univariate and bivariate models by applying simulated out-of-sample methods to 170 U.S. monthly macroeconomic time series spanning 1959 - 2002. The iterated forecasts typically outperform the direct forecasts, particularly if the models can select long lag specifications. The relative performance of the iterated forecasts improves with the forecast horizon.
\end{abstract}

Keywords: multistep forecasts, VAR forecasts, forecast comparisons

JEL Numbers: C32, E37, E47 


\section{Introduction}

A forecaster making a multiperiod time series forecast - for example, forecasting the unemployment rate six months hence - confronts a choice between using a oneperiod model iterated forward, or instead using a multiperiod model estimated with a loss function tailored to the forecast horizon. In the case of univariate linear models and quadratic loss, the "iterated" forecast (sometimes called a "plug-in" forecast) entails first estimating an autoregression, then iterating upon that autoregression to obtain the multiperiod forecast. In contrast, the forecast based on the multiperiod model - which, following the literature, we shall call the "direct" forecast - entails regressing a multiperiod-ahead value of the dependent variable on current and past values of the variable. For example, the direct forecast of the unemployment rate six months from now might entail the regression of the unemployment rate, six months hence, against a constant and current and past values of the unemployment rate. But which forecast, the iterated or the direct, should the forecaster use in practice?

The theoretical literature on this problem tends to emphasize the advantages of the direct over indirect forecasts. The idea that direct multiperiod forecasts can be more efficient than iterated forecasts dates at least to Cox (1961), who made the suggestion in the context of exponential smoothing, and to Klein (1968), who suggested direct multiperiod estimation of dynamic forecasting models. Contributions to the theory of iterated vs. direct forecasts include Findley (1983, 1985), Weiss (1991), Tiao and Xu (1993), Lin and Granger (1994), Tiao and Tsay (1994), Clements and Hendry (1996), Bhansali (1996, 1997), Kang (2003), Chevillon and Hendry (2005), and Schorfheide (2005). Bhansali (1999) provides a nice survey of this theoretical literature, and Ing (2003) gives a complete treatment of first-order asymptotics for stationary autoregressions.

Choosing between iterated and direct forecasts involves a tradeoff between bias and estimation variance: the iterated method produces more efficient parameter estimates than the direct method, but it is prone to bias if the one-step ahead model is misspecified. Ignoring estimation uncertainty, if both the iterated model and the direct model have $p$ lags of the dependent variable but the true autoregressive order exceeds $p$, then the 
asymptotic mean squared forecast error (MSFE) of the direct forecast typically is less than (and cannot exceed) the MSFE of the iterated forecast (e.g. Findley (1983)). On the other hand, if the true autoregressive order is $p$ or less, then (still ignoring estimation uncertainty) the MSFEs of the direct and iterated methods are the same; because the iterated parameter estimator is more efficient, the MSFE including estimation uncertainty is less for the iterated method when the autoregressive order is correctly specified. Because it seems implausible that typically low-order autoregressive models are correctly specified, in the sense of estimating the best linear predictor, the theoretical literature tends to conclude that the robustness of the direct forecast to model misspecification makes it a more attractive procedure than the bias-prone iterated forecast (Bhansali (1999), Ing (2003)).

Because the relative efficiency of iterated vs. direct forecasts is theoretically ambiguous and depends on the unknown population best linear projection, the question of which method to choose is an empirical one. Given the practical importance of the question, there are surprisingly few empirical studies of the relative performance of iterated vs. direct forecasts. Findley $(1983,1985)$ studies univariate models of two of Box and Jenkin's (1976) series (chemical process temperature and sunspots), and Liu (1996) studies univariate autoregressive forecasts of four economic time series. Ang, Piazzesi, and Wei (2005) find that, at least during the 1990s, iterated forecasts of U.S. GDP growth outperform direct forecasts using a measure of short-term interest rates and the term spread. The largest empirical study we are aware of is Kang (2003), who studies univariate autoregressive models of nine U.S. economic time series with mixed results, concluding that the direct method "may or may not improve forecast accuracy" relative to the iterated method (Kang, 2003, p. 398).

This paper undertakes a large-scale empirical comparison of iterated vs. direct forecasts using data on 170 U.S. macroeconomic time series variables, available monthly from 1959 to 2002. Rather than narrowing in on individual series, this study considers the larger questions of whether the iterated or direct forecasts are more accurate on average for the population of U.S. macroeconomic time series, and whether the distribution of MSFEs for direct forecasts is statistically and substantively below the distribution of MSFEs for iterated forecasts. Using these data, we compare iterated and 
direct forecasts based on univariate autoregressions and bivariate vector autoregressions; in both cases, we consider models with fixed lag order and models with data-dependent lag order choices, using the Akaike Information Criterion (AIC) or, alternatively, the Bayes Information Criterion (BIC). ${ }^{1}$ Multiperiod forecasts are computed for horizons of $3,6,12$, and 24 months. ${ }^{2}$ The experimental design uses a pseudo out-of-sample (or "recursive") forecasting framework; for example, forecasts for the twelve months from January 1985 to December 1985 are computed from models estimated and selected using only data available through December 1984.

This study yields surprisingly sharp results. First, iterated forecasts tend to have lower sample MSFEs than direct forecasts, particularly if the lag length in the one-period ahead model is selected by AIC. Second, these improvements tend to be modest, as one would expect if the main source of the improvements is reduction in estimation uncertainty of the parameters. Third, direct forecasts become increasingly less desirable as the forecast horizon lengthens; this too is consistent with the efficiency of the iterated forecasts outweighing the robustness of the direct forecasts. Fourth, for series measuring wages, prices, and money, direct forecasts improve upon iterated forecasts based on loworder autoregressions, but not upon iterated forecasts from high-order autoregressions, a finding that is consistent with these series having, in effect, a large moving average root (or long lags in the optimal linear predictor), as suggested by Nelson and Schwert (1977) and Schwert (1987). In contrast, iterated forecasts from low-order autoregressive models outperform direct forecasts for real activity measures and the other macroeconomic variables in our data set.

\footnotetext{
${ }^{1}$ Because possible model misspecification is central to this comparison, data-dependent lag order choice can play an important role: selecting a high-order one-period model can reduce bias but increase estimation uncertainty, and thus increase total MSFE, relative to a lower order direct model (Bhansali (1997)).

${ }^{2}$ Following the literature we consider direct $h$-step versus one-step ahead iterated forecasts. In principle, it would also be possible to construct iterated forecasts from $k$ step ahead models, where $k<h$, and $h / k$ is an integer.
} 


\section{Forecasting Models and Methods of Comparison}

This section describes the iterated and direct forecasting models and estimators. We begin with two general observations.

First, many macroeconomic time series appear to be nonstationary in the sense of having one or more unit roots, while the literature surveyed above focuses on stationary variables. ${ }^{3}$ The strategy adopted here is to transform the series of interest to approximate stationarity by taking its first or second difference as needed, to estimate the forecasting model, then to compute the $h$-step ahead forecast of the original series produced by that model. For example, the logarithm of real GDP is first transformed by taking its first difference, $\Delta \log G D P_{t}$, the forecasting models are estimated using $\Delta \log G D P_{t}$, and these models are then used to compute the forecast of the level of the logarithm of GDP, $h$ periods ahead. The transformations used for each series are discussed in the next section and in the data appendix.

Second, all forecasts are recursive (pseudo out-of-sample), that is, forecasts are based only on values of the series up to the date at which the forecast is made. Parameters are then reestimated in each period, for each forecasting model, using data from the beginning of the sample through the current forecasting date. For forecasts entailing data-based model selection, the order of the model is also selected recursively, and thus can change over the sample as new information is added to the forecast data set.

\subsection{Univariate Models}

Let $X_{t}$ denote the level or logarithm of the series of interest. The objective is to compute forecasts of $X_{t+h}$, using information at time $t$. Let $y_{t}$ denote the stationary transformation of the series after taking first or second differences. Specifically, suppose that $X_{t}$ is integrated of order $d\left(\right.$ is $\mathrm{I}(d)$ ); then $y_{t}=\Delta^{d} X_{t}$, where $d=0,1$, or 2 as appropriate.

Iterated $\boldsymbol{A R}$ forecasts. The one-step ahead AR model for $y_{t}$ is

\footnotetext{
${ }^{3}$ A notable exception is Chevillon and Hendry (2005), which compares iterated and direct forecasts for I(1) autoregressions. Long-horizon iterated forecasts in the local-tounity autogression are studied in Stock (1997), and these methods appear well-suited for studying direct forecasts as well.
} 


$$
y_{t+1}=\alpha+\sum_{i=1}^{p} \phi_{i} y_{t+1-i}+\varepsilon_{t}
$$

For the iterated AR forecasts, the parameters $\alpha, \phi_{1}, \ldots, \phi_{p}$ in (2.1) are estimated recursively by OLS, and the forecasts of $y_{t+h}$ are constructed recursively as,

$$
\hat{y}_{t+h / t}^{I}=\hat{\alpha}+\sum_{i=1}^{p} \hat{\phi}_{i} \hat{y}_{t+h-i / t}^{I}
$$

where $\hat{y}_{j / t}=y_{j}$ for $j \leq t$. Forecasts of $X_{t+h}$ are then computed by accumulating the values of $\hat{y}_{t+k / t}^{I}$ as appropriate in the $\mathrm{I}(0), \mathrm{I}(1)$ and $\mathrm{I}(2)$ cases:

$$
\hat{X}_{t+h \mid t}^{I}=\left\{\begin{array}{l}
\hat{y}_{t+h \mid t}^{I} \text { if } X_{t} \text { is } \mathrm{I}(0) \\
X_{t}+\sum_{i=1}^{h} \hat{y}_{t+i \mid t}^{I} \quad \text { if } X_{t} \text { is I(1) } \\
X_{t}+\sum_{i=1}^{h} \sum_{j=1}^{i} \hat{y}_{t+j \mid t}^{I} \quad \text { if } X_{t} \text { is } \mathrm{I}(2)
\end{array}\right.
$$

Direct forecasts. The direct estimates of the parameters are the recursive minimizers of the mean squared error of the $h$-step ahead criterion function. Accordingly, the parameters are estimated by the OLS regression in which the regressors are a constant and $y_{t}, \ldots, y_{t-p+1}$ and the dependent variable is $y_{t+h}^{h}$, where

$$
y_{t+h}^{h}=\left\{\begin{array}{l}
X_{t+h} \text { if } X_{t} \text { is } \mathrm{I}(0) \\
X_{t+h}-X_{t} \text { if } X_{t} \text { is I(1) } \\
\sum_{i=1}^{h} \sum_{j=1}^{i} \Delta^{2} X_{t+j}=X_{t+h}-X_{t}-h \Delta X_{t} \text { if } X_{t} \text { is I( }(2)
\end{array}\right.
$$

The direct forecasting regression model is, 


$$
y_{t+h}^{h}=\beta+\sum_{i=1}^{p} \rho_{i} y_{t+1-i}+\varepsilon_{t+h}
$$

The direct estimator of the coefficients is obtained by the recursive estimation of (2.5) by OLS, where data through period $t$ are used (so that the last observation includes $y_{t}^{h}$ on the left hand side of the regression). The direct forecasts of $y_{t+h}^{h}$ are

$$
\hat{y}_{t+h}^{D, h}=\hat{\beta}+\sum_{i=1}^{p} \hat{\rho}_{i} y_{t+1-i}
$$

Forecasts of $X_{t+h}$ are then computed from the $\hat{y}_{t+h}^{D, h}$ as appropriate in the I(0), I(1) and I(2) cases: $\hat{X}_{t+h / t}^{D}=\hat{y}_{t+h / t}^{D, h}$ for I $(0), \quad \hat{X}_{t+h / t}^{D}=\hat{y}_{t+h}^{D, h}+X_{t}$ for I(1) and $\hat{X}_{t+h / t}^{D}=\hat{y}_{t+h}^{D, h}+X_{t}+h \Delta X_{t}$ for $\mathrm{I}(2){ }^{4}$

Lag length determination. Four different methods were used to determine the lag order $p$ : (1) $p=4$ (fixed); (2) $p=12$ (fixed); (3) $p$ chosen by the Akaike Information Criterion (AIC), with $0 \leq p \leq 12$, and (4) $p$ chosen by the Bayes Information Criterion (BIC), with $0 \leq p \leq 12$. For the iterated forecasts, the AIC and BIC were computed using the standard formulas based on the sum of squared residuals (SSR) from the one-step ahead regression. For the direct forecasts, the AIC and BIC were computed using the SSR from the estimated $h$-step ahead regression (2.5). The AIC and BIC were recomputed at each date, so the order of the selected forecasting model can change from one period to the next, where the model selection and parameter estimates are based only on data through the date of the forecast (period $t$ ).

These four choices cover leading cases of theoretical interest. If the true lag order $p_{0}$ is finite and if the maximum lag considered exceeds $p_{0}$, then the BIC provides a consistent estimator of $p_{0}$ and the iterated estimator with BIC is asymptotically efficient.

\footnotetext{
${ }^{4}$ As an alternative, direct forecasts could be computed by first estimating regressions of $y_{t+i}$ onto $\left(1, y_{t}, y_{t-1}, \ldots y_{t+1-p}\right)$ for $i=1, \ldots, h$, and then accumulating the forecasts of $y_{t+i}$ to form forecasts of $y_{t+h}^{h}$. Because each regression uses the same set of regressors, these forecasts will be identical to those in (2.6) when data over the sample period are used.
} 
If $p_{0}$ is infinite, then the direct estimator with AIC model selection achieves an efficiency bound for direct estimators and this bound is below that for all iterated estimators (see Bhansali (1996) for a precise statement of this result; he shows that the direct estimator bound also is achieved using Shibata's (1980) lag length selector). In finite samples, however, BIC and AIC lag length selection introduces additional sampling uncertainty and the short (4 lag) and long (12 lag) fixed-lag autoregressions provide benchmarks against which to compare the BIC and AIC forecasts. ${ }^{5}$

\subsection{Multivariate Models}

We also consider iterated and direct forecasts computed using bivariate vector autoregressions (VARs). For two series $i$ and $j$, the iterated VARs are specified in terms of the stationary transforms $y_{i t}$ and $y_{j t}$. The iterated forecast is then obtained by iterating forward the VAR and then applying the transformation (2.3). The $h$-step direct forecast for series $i$ is obtained from the OLS regression of $y_{i, t+h}^{h}$ against a constant and $p$ lags each of $y_{i t}$ and $y_{j t}$. In both the iterated and direct models, the same number of lags $p$ is used for both regressors. The same four methods of lag determination are used as in the analysis of the univariate models.

\subsection{Estimation and Forecast Sample Periods}

Let $T_{0}$ denote the first observation used in estimation of the regressions, $T_{1}$ denote the date at which the first pseudo out-of-sample forecast is made, and $T_{2}$ denote the date at which the final pseudo out-of-sample forecast is made. The date $T_{0}$ is the date at which the first observation is available (for most series, 1959:1), plus twelve (because twelve lags are used for the long-lagged models), plus the order of integration of the series (to allow for first and second differences). For most series, the initial forecast date $T_{1}$ is 1979:1; for series that start after 1959:1, $T_{1}$ is the later of 1979:1 or the first observation for which all regressions can be estimated using a minimum of 120 observations. The

\footnotetext{
${ }^{5}$ Other possible lag-length selection methods are possible but are not pursued here. For example, Bhansali (1999) and Schorfheide (2005) suggest selecting the order of the iterated model based on the h-step ahead SSR of the iterated forecasts, rather than (as is conventional and as we do) based on the one-step ahead SSR.
} 
final forecast date depends on the forecast horizon, and is the date of the last available observation (2002:12) minus the forecast horizon $h$. Thus, for most series, pseudo out-ofsample forecasts $\hat{X}_{t+h}$ were computed for $t=1979: 1$ to 2002:12 $-h$.

The pseudo out-of-sample forecast error is $e_{t+\mathrm{h}}=\hat{X}_{t+h}-X_{t+h}$, and the sample MSFE is,

$$
M S F E=\frac{1}{T_{2}-T_{1}+1} \sum_{t=T_{1}}^{T_{2}} e_{t+h}^{2}
$$

The sample MSFE is computed for each series (170 series), for each forecasting method (iterated, with 4 lag choices, and direct, with 4 lags choices), and for each horizon $(3,6$, 12, and 24 months). For a given series and horizon, the empirical efficiency of comparable direct and indirect forecasts is assessed by comparing the respective MSFEs.

\subsection{Parametric Bootstrap Method for Comparing Iterated v. Direct Forecasts}

1.The sample MSFE might be less for a direct than an iterated forecast either because the direct forecast is more efficient in population or because of sampling variability. For a single series, the null hypothesis that a direct forecast fails to improve upon an indirect forecast can be tested using suitable versions of tests proposed by West (1996) and Clark and McCracken (2001) for comparing simulated out-of-sample forecasts. Our focus, however, is on whether the direct method improves upon the iterated method on average over the population of macroeconomic variables of interest. Thus the objects of interest in this study are summary measures of the distribution of the relative MSFEs, for example the mean relative MSFE of the direct estimator, relative to the iterated estimator, across the population of U.S. macroeconomic series, from which we have a sample of 170 series. This comparison of empirical distributions of direct and iterated estimators goes beyond the theoretical results available in the forecast evaluation literature.

To assess the statistical significance of our summary statistics, we therefore implemented a parametric bootstrap that examined the spread of the distribution of 
relative MSFEs under the null hypothesis that the iterated forecasting model is correctly specified, so that the iterated forecast is efficient. The parametric bootstrap has the following steps.

1. For each series $i, i=1, \ldots, 170$, an autoregressive model of order $p_{i}$ is estimated using the full sample, producing the (one-step ahead) residuals $e_{i t}$.

2. Previous research suggests that these series are well modeled by a factor model with a small number of factors (e.g. Stock and Watson (2002a, 2002b)). Accordingly, a static factor model with four factors is fit to these residuals, where the factor loadings and error variances are estimated using principal components. Separate factor models (different factor loadings and idiosyncratic variances) were estimated in the pre-1982:12 and post-1983:1 periods, where the break point was chosen approximately to coincide with the decline in volatility of many U.S. macroeconomic time series (McConnell and Perez-Quiros (2000), Kim and Nelson (1999)).

3. Using the estimated parameters from the dynamic factor models, a pseudorandom data set consisting of 170 series was computed, where the sample periods for the pseudo data are the same as the actual data. From these pseudo-random data, recursive iterated and direct forecasts are computed as described above, along with their MSFEs. This process is repeated 200 times. This produces an empirical distribution of direct MSFEs, relative to iterated MSFEs, under the hypothesis that the true AR lag length is $p_{i}, i=1, \ldots, 170$.

4. This procedure is repeated for each of the four lag selection methods. For $p=4$ (fixed), $p_{i}$ is fixed at 4 , and similarly for $p=12$ (fixed). For the AIC method, $p_{i}$ is determined by AIC prior to estimation in step \#1, and similarly for the BIC method.

This algorithm provides an estimate of the distribution of relative MSFEs under the null hypothesis that the iterated model is correctly specified (so that the iterated model is asymptotically efficient), where this distribution allows for both sampling uncertainty in the MSFEs and heterogeneity among and time variation of the 
autoregressive processes. This distribution allows for a comparison of the observed population distribution of relative MSFEs to their null distribution. This distribution also can be used to compute bootstrap $p$-values. For example, consider the comparison of the direct estimator with $p=4$ to the iterated estimator with $p=4$. The bootstrap $p$-value of the hypothesis that the median relative MSFE (where the median is computed across all 170 series for the given horizon) equals its population value that would obtain were the iterated model correctly specified so that the iterated estimator is efficient, against the alternative that the direct estimator is more efficient, is the fraction of the 200 bootstrap draws of the median that are less than the median ratio actually observed in the data.

\section{The Data}

The data set consists of 170 major monthly U.S. macroeconomic time series. The full data set spans 1959:1 - 2002:12, and most series are available over this full sample. The data set consists of five categories of series:

(A) Income, output, sales, and capacity utilization (38 Series);

(B) Employment and unemployment (27 Series);

(C) Construction, inventories and orders (37 Series);

(D) Interest rates and asset prices (33 Series); and

(E) Nominal prices, wages, and money (35 Series).

The series and their spans are listed in the data appendix.

The series were subject to three transformations and manipulations. First, series that represent quantities, indexes, and price levels were transformed to logarithms; interest rates, unemployment rates, etc. were left in the original levels; this yields the $X_{i t}$ series in the notation of Section 2.

Second, these series were then differenced so that the resulting series were integrated of order zero, yielding the $y_{i t}$ series in the notation of Section 2. Generally speaking, real quantities and real prices were treated as I(1). For our primary set of results, we treated nominal prices, wages, and money as I(1). There is disagreement among practitioners about whether it is best to treat these series as I(1) or I(2), however, 
so we repeated the analysis treating the series in category (E), prices, wages, and money, as I(2). The results of this sensitivity analysis are discussed briefly in the next section.

Third, a few of the resulting $y_{i t}$ series contained large outliers. So that these outliers would not dominate the results, observations were dropped when $\left|y_{i t}\right|$ exceeded its median by more than six times its interquartile range.

\section{Results for Univariate Autoregressions}

Table 1 summarizes the distributions of the ratios of the MSFE of the direct forecast to the MSFE of the iterated forecast, where the forecasts are based on the same method of lag selection, for different forecast horizons. For example, across the 170 series, when $p=4$ lags are used for both the iterated and direct forecast and the forecast horizon is $h=3$, the mean relative MSFE is 0.99 , indicating that the direct estimator on average makes a very slight improvement over the indirect estimator, at least by this measure. In $10 \%$ of the 170 series, relative MSFE is less than .97 at this horizon, while in $10 \%$ of the series the relative MSFE exceeds 1.02. The numbers in parentheses in Table 1 are the bootstrap $p$-values for the test of the hypothesis that the iterated estimator is efficient, computed as described in Section 2.4. For example, the bootstrap $p$-value of the mean relative MSFE for the $p=4$ lag model at horizon $h=3$ is $<.005$; according to the bootstrap null distribution, were the iterated model correctly specified, the probability of observing a mean relative MSFE of .99 or less is less than $0.5 \%{ }^{6}$

Inspection of Table 1 suggests that whether the iterated or direct estimator is preferred depends on the method of lag selection. For the short lag selection methods ( $p$ $=4$ and $\mathrm{BIC}$ ), the direct estimator is preferred; this is particularly true for the BIC, where the improvements in the lower tail of the distribution are substantial, at least through the 12-month horizon. According to the bootstrap $p$-values, these improvements generally are statistically significant. In contrast, within the long-lag models, the iterated estimator is preferable, and the direct estimator typically does not improve substantially upon the iterated estimator. At the longer 24-month horizon, the iterated forecast is generally

${ }^{6}$ If the iterated model is correctly specified, then the direct estimator is inefficient and the relative MSFE ratio would tend to exceed one. 
preferable to the direct forecast for all four lag selection methods. Indeed, at this horizon the direct forecasts can be markedly worse than the iterated forecasts: the $90^{\text {th }}$ percentile of the distribution of relative MSFEs at $h=24$ exceeds 1.2 for all four lag methods. These results suggest that the robustness of the direct estimator is outweighed by its larger variance. ${ }^{7}$

Table 2 breaks down the overall results in Table 1 into two categories of series, the 35 series on nominal prices, wages, and money, and the remaining 135 series. The conclusions are substantially different for these two sets of series. Once the price, wage, and money series are excluded, the iterated forecast is universally preferred to the direct forecast at all horizons. Even in the few cases that the direct estimator has a small $p$ value, the actual MSFE ratio is one or very nearly so, indicating that the improvement from the direct forecast is too small to be of practical forecasting value. In contrast, for the price, wage, and money series, the direct estimator provides statistically significant improvements over the indirect estimator at all horizons, and at all points in the distribution, for both short-lag models; in some cases, these improvements are large from a practical perspective (for example, the mean relative MSFE at $h=6$ and $h=12$ for the BIC model is .86). But using longer lags in the iterated model eliminates most if not all of the advantages of the direct forecast; for example, at $h=12$, the mean relative MSFE for the 4 lag forecasts is .87 , but this rises to 1.00 for the 12 lag forecasts, a value that is statistically significant but provides no practical improvement from using the direct method.

Table 3 summarizes the mean and median relative MSFEs of the various forecasts, all relative to the iterated 4-lag forecasts (so the entry for the iterated AR(4) column is 1.00 by construction), for all series together (part A) and for the two groups of non-price and price series separately (parts B and C). Also reported are the fraction of series among the 170 series for which a given forecast has the smallest MSFE at that

\footnotetext{
${ }^{7}$ As a check of this interpretation of the results, a referee suggested that we compute the results separately for the first and second half of the out-of-sample period. The variance component of the MSFE should be smaller in the second half because of the increased sample used for estimation, so that the relative performance of the direct forecast should improve. Indeed, the forecast errors did show a slight improvement in the relative forecast performance of the direct forecast in the second half of the out-of-sample period.
} 
horizon among the eight competitors. Several results stand out. If prices, wages, and money are excluded, then the iterated forecasts produce the lowest MSFEs in the clear majority of cases; the forecasts that are most frequently best are the short-lag iterated forecasts. On average, direct forecasts produce higher MSFEs than the iterated AR(4), sometimes by a substantial margin. The relative performance of the iterated forecasts improves as the horizon lengthens. For the price, wage, and money series, the short-lag iterated forecasts are not successful, and for nearly half these series the direct forecasts are better at short horizons. As the horizon lengthens, however, the iterated forecasts become more desirable.

The fact that short-lag iterated forecasts are most successful for the non-price series and long-lag iterated forecasts are most successful for the price series suggests that iterated forecasts with a data-dependent lag choice that can select long-lagged models should be best in some average sense. This is in fact the case. For all series combined (Table 3, part A), the mean and median MSFE of the iterated AIC forecast, relative to the iterated AR(4), is as small or smaller than the relative MSFEs of all the other forecasts, at all horizons.

As a sensitivity check, the results for the price, wage, and money variables (the variables in category $\mathrm{E}$ in the data appendix) were recomputed, treating these variables as $\mathrm{I}(2)$ instead of $\mathrm{I}(1)$. The results are summarized in part D of Table 3; full results are available on the $\mathrm{Web}^{8}$. In the I(2) specification, the iterated $\mathrm{AR}(4)$ forecasts have larger MSFEs, relative to the other forecasts, than they do in the I(1) specification, so that the mean relative MSFEs are smaller in part D than in part C. Adjusting for this difference in the denominators, however, one can see that the general pattern in part D is the same as in the I(1) specifications in part D. In particular, the long lag specifications outperform the short-lag specifications, and the iterated long-lag forecasts tend to have the best average performance, especially as the horizon increases.

The different results for the wage and price series suggest that the population best linear projections for the non-price series tend to be short, whereas they tend to be long for the price, wage, and money series. In particular, there could be large moving average root in ARIMA models of prices, wages, and money, where the number of autoregressive

\footnotetext{
${ }^{8}$ www.wws.princeton.edu/ mwatson/
} 
lags is short. This possibility has been previously suggested by Nelson and Schwert (1977) and Schwert (1987) and is consistent with the long-lag lengths for backwardlooking Phillips curve specifications that Brayton, Roberts, and Williams (1999) argue is appropriate for postwar U.S. data. To examine this possibility, Table 4 reports estimated $\operatorname{ARIMA}(2,1,1)$ and $\operatorname{ARIMA}(1,2,1)$ models for the eight wage and price inflation series for which a direct forecast exhibited the greatest improvement, relative to the iterated $\mathrm{AR}(4)$ forecast. In all cases, the MA coefficient is large, in a few cases exceeding .9. This large moving average root occurs in both the I(1) specifications and the I(2) specifications for these series, so it is not a simple consequence of overdifferencing. These large moving average coefficients are consistent with a slow decay in the coefficients of the optimal linear predictor for the price and wage series and are consistent with the relatively poor performance of the short-lag iterated estimators, and the relatively good performance of the long-lag direct and iterated estimators, for these series.

\section{Results for Bivariate Forecasts}

This data set contains a total of $170 \times 169=28,730$ different possible pairs of series. To keep the computations tractable, we used a stratified random subsample of these VARs. There are five categories of series, listed as (A) through (E), in Section 3. This produces 10 possible pairs of nonrepeated series categories $(\mathrm{AB}, \mathrm{AC}, . ., \mathrm{BC}$, BD,..,DE). From each pair of categories, 200 pairs of series are randomly drawn (one from each category, with replacement), for a total of 2000 pairs of series. This set of 2000 pairs of series constitutes the data set for the bivariate forecasts. At each horizon and for each forecasting method (iterated or direct, four lag selection methods), a total of 4000 forecasts are computed from the 2000 pairs, one for each series in the pair.

The iterated and direct forecasts are compared, for the same lag length selection

method, in Table 5, for all the series combined (this is the bivariate counterpart of Table 1). The conclusions are similar to those for the univariate models. Generally speaking, the long-lag ( $p=12$ or AIC) direct forecasts offer little or no average improvements over 
the long-lag iterated forecasts. For a subset of the pairs, the direct forecasts have lower MSFEs than the iterated forecasts for the short-lag selection methods.

Table 6 summarizes the performance of the various forecasting methods, relative to the iterated VAR(4) benchmark (this is the bivariate counterpart of Table 3). The results are qualitatively similar to those found using the univariate models. For the pairs that do not contain a nominal price, wage or money series (part B of Table 3), the shortlag iterated methods are most frequently best, and the iterated methods outperform the direct methods in approximately three-fourths of the series. For the price, wage, and money series (part D), the short-lag iterated methods are infrequently best, and are beaten by the long-lag iterated methods and, at short horizons, the long-lag direct methods. At long horizons, the direct methods still outperform the iterated AR(4) benchmark for these series, but do not outperform the long-lag iterated method. Looking across all variables, the iterated method with AIC lag selection tends to produce the lowest, or nearly lowest, MSFE on average across all horizons.

\section{Discussion}

The main finding from this study is that, for our large data set of monthly U.S. macroeconomic time series, iterated forecasts tend to have smaller MSFEs than direct forecasts, particularly if the iterated forecasts are computed using AIC lag length selection. The relative performance of the direct forecasts deteriorates as the forecast horizon increases. These findings are consistent with the view that the single-period models, upon which the iterated forecasts are based, are not badly misspecified in the sense that they provide good approximations to the best linear predictor; accordingly, the reduction in estimation variance arising from estimating the one-period ahead model outweighs the reduction in bias obtained from the direct multiperiod model.

There is considerable heterogeneity in these data with respect to the best lag order of the one-period model: for nominal price, wage, and money series, a long lag order is indicated, whereas for the other series a short lag order is more appropriate. Overall, this heterogeneity appears to be handled adequately by using AIC lag length selection when specifying the model for the iterated forecast. 
It is interesting to note that these findings in favor of the iterated forecasts are at odds with some of the theoretical literature, which emphasizes the robustness and bias reduction of the direct forecasts in contrast to the special parametric, finite-lag assumptions that underlie optimality properties for the iterated forecasts (cf. Bhansali (1999), Ing (2003)). It appears that, in practice, the robustness and bias reduction obtained using direct forecasts does not justify the price paid in terms of increased sampling variance. 


\section{Data Appendix}

This appendix lists the time series used in the empirical analysis. The series were either taken directly from the DRI-McGraw Hill Basic Economics database, in which case the original mnemonics are used, or they were produced by authors' calculations based on data from that database, in which case the authors' calculations and original DRI/McGraw series mnemonics are summarized in the data description field. Following the series name is a transformation code, the sample period for the data series, and a short data description. The transformations are (Lev) level of the series; $(\Delta)$ first difference; (Ln) logarithm of the series; $(\Delta \mathrm{Ln})$ first difference of the logarithm. The following abbreviations appear in the data descriptions: $\mathrm{SA}=$ seasonally adjusted; $\mathrm{NSA}=$ not seasonally adjusted; SAAR $=$ seasonally adjusted at an annual rate; $\mathrm{AC}=$ Authors' calculations.

\begin{tabular}{|c|c|c|c|}
\hline Series & Trans. & Sample Period & Description \\
\hline \multicolumn{4}{|c|}{ (A) Income, Output, Sales, Capacity Utilization } \\
\hline $\mathrm{msmq}$ & $\Delta \mathrm{Ln}$ & 1967:1-2001:7 & sales, business - manufacturing (chained) \\
\hline ips11 & $\Delta \mathrm{Ln}$ & 1959:1-2002:12 & industrial production index - products, total \\
\hline ips299 & $\Delta \mathrm{Ln}$ & 1959:1-2002:12 & industrial production index - final products \\
\hline ips12 & $\Delta \mathrm{Ln}$ & 1959:1-2002:12 & industrial production index - consumer goods \\
\hline ips13 & $\Delta \mathrm{Ln}$ & 1959:1-2002:12 & industrial production index - durable consumer goods \\
\hline ips18 & $\Delta \mathrm{Ln}$ & 1959:1-2002:12 & industrial production index - nondurable consumer goods \\
\hline ips25 & $\Delta \mathrm{Ln}$ & 1959:1-2002:12 & industrial production index - business equipment \\
\hline ipi & $\Delta \mathrm{Ln}$ & 1959:1-2002:10 & industrial production:intermediate products $(1992=100$, sa) \\
\hline ips32 & $\Delta \mathrm{Ln}$ & 1959:1-2002:12 & industrial production index - materials \\
\hline ips34 & $\Delta \mathrm{Ln}$ & 1959:1-2002:12 & industrial production index - durable goods materials \\
\hline ips38 & $\Delta \mathrm{Ln}$ & 1959:1-2002:12 & industrial production index - nondurable goods materials \\
\hline ips43 & $\Delta \mathrm{Ln}$ & 1959:1-2002:12 & industrial production index - manufacturing (sic) \\
\hline ipd & $\Delta \mathrm{Ln}$ & 1959:1-2002:10 & industrial production:durable manufacturing $(1992=100$, sa $)$ \\
\hline ipn & $\Delta \mathrm{Ln}$ & 1959:1-2002:10 & industrial production:nondurable manufacturing $(1992=100, \mathrm{sa})$ \\
\hline ipmin & $\Delta \mathrm{Ln}$ & 1959:1-2002:10 & industrial production:mining $(1992=100$, sa $)$ \\
\hline iput & $\Delta \mathrm{Ln}$ & 1959:1-2002:10 & industrial production:utilities (1992-=100,sa) \\
\hline utl10 & Lev & 1967:1-2002:12 & capacity utilization - total index \\
\hline utl11 & Lev & 1959:1-2002:12 & capacity utilization - manufacturing (sic) \\
\hline utl13 & Lev & 1967:1-2002:12 & capacity utilization - durable manufacturing (naics) \\
\hline utl25 & Lev & 1967:1-2002:12 & capacity utilization - nondurable manufacturing (naics) \\
\hline utl35 & Lev & 1967:1-2002:12 & capacity utilization - mining naics $=21$ \\
\hline utl36 & Lev & 1967:1-2002:12 & capacity utilization - electric and gas utilities \\
\hline gmpyq & $\Delta \mathrm{Ln}$ & 1959:1-2002:12 & personal income (chained) (series \#52) (bil 92\$,saar) \\
\hline gmyxpq & $\Delta \mathrm{Ln}$ & 1959:1-2002:12 & personal income less transfer payments (chained) (\#51) (bil 92\$,saar) \\
\hline gmcq & $\Delta \mathrm{Ln}$ & 1967:1-2002:12 & personal consumption expend (chained) - total (bil 92\$,saar) \\
\hline gmcdq & $\Delta \mathrm{Ln}$ & 1967:1-2002:12 & pers consumption expend (chained) - total durables (bil 1996\$,saar) \\
\hline gmcnq & $\Delta \mathrm{Ln}$ & 1967:1-2002:12 & personal consumption expend (chained) - nondurables (bil 96\$,saar) \\
\hline gmcsq & $\Delta \mathrm{Ln}$ & 1967:1-2002:12 & personal consumption expend (chained) - services (bil 92\$,saar) \\
\hline gmcanq & $\Delta \mathrm{Ln}$ & 1967:1-2002:12 & personal cons expend (chained) - new cars (bil 1996\$,saar) \\
\hline wtq & $\Delta \mathrm{Ln}$ & 1959:1-2001:7 & merch wholesalers:total (mil of chained 1996 dollars)(sa) \\
\hline wtdq & $\Delta \mathrm{Ln}$ & 1959:1-2001:7 & merch wholesalers:durable goods total (mil of chained 1996 dollars)(sa) \\
\hline msdq & $\Delta \mathrm{Ln}$ & 1959:1-2001:7 & mfg \& trade:mfg; durable goods (mil of chained 1996 dollars)(sa) \\
\hline
\end{tabular}




\begin{tabular}{|c|c|c|c|}
\hline msmtq & $\Delta \mathrm{Ln}$ & 1959:1-2001:7 & mfg \& trade:total (mil of chained 1996 dollars)(sa) \\
\hline msnq & $\Delta \mathrm{Ln}$ & 1959:1-2001:7 & mfg \& trade:mfg;nondurable goods (mil of chained 1996 dollars)(sa) \\
\hline wtnq & $\Delta \mathrm{Ln}$ & 1959:1-2001:7 & merch wholesalers:nondurable goods (mil of chained 1996 dollars)(sa) \\
\hline rtdrq & $\Delta \mathrm{Ln}$ & 1967:1-2001:4 & retail sales durables, real (rtdr/pucd) (AC) \\
\hline rtnrq & $\Delta \mathrm{Ln}$ & 1967:1-2001:4 & retail sales nondurables, real (rtnr/pu882) (AC) \\
\hline ips10 & $\Delta \mathrm{Ln}$ & 1959:1-2002:12 & industrial production index - total index \\
\hline \multicolumn{4}{|r|}{ (B) Employment and Unemployment } \\
\hline Ipnag & $\Delta \mathrm{Ln}$ & 1959:1-2002:12 & employees on nonag. payrolls:total (thous.,sa) \\
\hline Ihu26 & Lev & 1959:1-2002:12 & unemploy.by duration:persons unempl.15 to 26 wks (thous.,sa) \\
\hline Ipgd & $\Delta \mathrm{Ln}$ & 1959:1-2002:12 & employees on nonag. payrolls:goods-producing (thous.,sa) \\
\hline Ihu15 & Lev & 1959:1-2002:12 & unemploy.by duration:persons unempl.15 wks + (thous.,sa) \\
\hline Ip & $\Delta \mathrm{Ln}$ & 1959:1-2002:12 & employees on nonag payrolls:total, private (thous,sa) \\
\hline Ipcc & $\Delta \mathrm{Ln}$ & 1959:1-2002:12 & employees on nonag. payrolls:contract construction (thous.,sa) \\
\hline Ihelx & $\mathrm{Ln}$ & 1959:1-2002:12 & employment:ratio; help-wanted ads:no. unemployed clf \\
\hline Ihu5 & Lev & 1959:1-2002:12 & unemploy.by duration:persons unempl.less than 5 wks (thous.,sa) \\
\hline Ihu14 & Lev & 1959:1-2002:12 & unemploy.by duration:persons unempl.5 to 14 wks (thous.,sa) \\
\hline Ipsp & $\Delta \mathrm{Ln}$ & 1959:1-2002:12 & employees on nonag. payrolls:service-producing (thous.,sa) \\
\hline Iptu & $\Delta \mathrm{Ln}$ & 1959:1-2002:12 & employees on nonag. payrolls:trans. \& public utilities (thous.,sa) \\
\hline Ipt & $\Delta \mathrm{Ln}$ & 1959:1-2002:12 & employees on nonag. payrolls:wholesale \& retail trade (thous.,sa) \\
\hline Ipfr & $\Delta \mathrm{Ln}$ & 1959:1-2002:12 & employees on nonag. payrolls:finance,insur.\&real estate (thous.,sa \\
\hline Ips & $\Delta \mathrm{Ln}$ & 1959:1-2002:12 & employees on nonag. payrolls:services (thous.,sa) \\
\hline Ipgov & $\Delta \mathrm{Ln}$ & 1959:1-2002:12 & employees on nonag. payrolls:government (thous.,sa) \\
\hline IW & Dif & 1964:1-2002:12 & avg. weekly hrs. of prod. wkrs.:total private (sa) \\
\hline Iphrm & Lev & 1959:1-2002:12 & avg. weekly hrs. of production wkrs.:manufacturing (sa) \\
\hline Ipmosa & Lev & 1959:1-2002:12 & avg. weekly hrs. of prod. wkrs.:mfg.,overtime hrs. (sa) \\
\hline Ihu680 & Lev & 1959:1-2002:12 & unemploy.by duration:average(mean)duration in weeks (sa) \\
\hline Ihur & Lev & 1959:1-2002:12 & unemployment rate:all workers, 16 years \& over $(\%, \mathrm{sa})$ \\
\hline Ipen & $\Delta \mathrm{Ln}$ & 1959:1-2002:12 & employees on nonag. payrolls:nondurable goods (thous.,sa) \\
\hline Ipem & $\Delta \mathrm{Ln}$ & 1959:1-2002:12 & employees on nonag. payrolls:manufacturing (thous.,sa) \\
\hline Ihel & $\Delta \mathrm{Ln}$ & 1959:1-2002:12 & index of help-wanted advertising in newspapers $(1967=100 ; \mathrm{sa})$ \\
\hline Iped & $\Delta \mathrm{Ln}$ & 1959:1-2002:12 & employees on nonag. payrolls:durable goods (thous.,sa) \\
\hline Ihem & $\Delta \mathrm{Ln}$ & 1959:1-2002:12 & civilian labor force:employed, total (thous.,sa) \\
\hline Ihnag & $\Delta \mathrm{Ln}$ & 1959:1-2002:12 & civilian labor force:employed, nonagric.industries (thous.,sa) \\
\hline Ipmi & $\Delta \mathrm{Ln}$ & 1959:1-2002:12 & employees on nonag. payrolls:mining (thous.,sa) \\
\hline \multicolumn{4}{|r|}{ (C) Construction, Inventories and Orders } \\
\hline hssou & $\mathrm{Ln}$ & 1959:1-2002:12 & housing starts:south (thous.u.)s.a. \\
\hline contc & $\Delta \mathrm{Ln}$ & 1964:1-2002:12 & construct.put in place:total priv \& public $1987 \$$ (mil\$,saar) \\
\hline conpc & $\Delta \mathrm{Ln}$ & 1964:1-2002:12 & construct.put in place:total private $1987 \$($ mil $\$$,saar) \\
\hline conqc & $\Delta \mathrm{Ln}$ & 1964:1-2002:12 & new construction put in place - public (c30) \\
\hline condo9 & $\mathrm{Ln}$ & 1963:1-2002:12 & construct.contracts:comm'l \& indus.bldgs(mil.sq.ft.floor sp.;sa) \\
\hline hniv & $\mathrm{Ln}$ & 1963:1-2002:12 & new 1-family houses for sale at end of month (thous,sa) \\
\hline $\mathrm{hnr}$ & $\mathrm{Ln}$ & 1963:1-2002:12 & new 1-family houses, month's supply @ current sales rate(ratio) \\
\hline hns & $\mathrm{Ln}$ & 1963:1-2002:12 & new 1-family houses sold during month (thous,saar) \\
\hline hsbr & $\mathrm{Ln}$ & 1959:1-2002:12 & housing authorized:total new priv housing units (thous.,saar) \\
\hline hswst & $\mathrm{Ln}$ & 1959:1-2002:12 & housing starts:west (thous.u.)s.a. \\
\hline hmob & $\mathrm{Ln}$ & 1959:1-2002:12 & mobile homes:manufacturers' shipments (thous.of units,saar) \\
\hline hsmw & Ln & 1959:1-2002:12 & housing starts:midwest(thous.u.)s.a. \\
\hline hsne & $\mathrm{Ln}$ & 1959:1-2002:12 & housing starts:northeast (thous.u.)s.a. \\
\hline hsfr & $\mathrm{Ln}$ & 1959:1-2002:12 & housing starts:nonfarm(1947-58);total farm\&nonfarm(1959-)(thous.,sa \\
\hline ivmtq & $\Delta \mathrm{Ln}$ & 1959:1-2001:7 & mfg \& trade inventories:total (mil of chained 1996)(sa) \\
\hline ivmfgq & $\Delta \mathrm{Ln}$ & 1959:1-2001:7 & inventories, business, mfg (mil of chained 1996 dollars, sa) \\
\hline ivmfdq & $\Delta \mathrm{Ln}$ & 1959:1-2001:7 & inventories, business durables (mil of chained 1996 dollars, sa) \\
\hline ivmfnq & $\Delta \mathrm{Ln}$ & 1959:1-2001:7 & inventories, business, nondurables (mil of chained 1996 dollars, sa) \\
\hline ivwrq & $\Delta \mathrm{Ln}$ & 1959:1-2001:7 & mfg \& trade inv:merchant wholesalers (mil of chained 1996 dollars)(sa) \\
\hline ivrrq & $\Delta \mathrm{Ln}$ & 1959:1-2001:7 & mfg \& trade inv:retail trade (mil of chained 1996 dollars)(sa) \\
\hline ivsrq & $\Delta \mathrm{Ln}$ & 1959:1-2001:7 & ratio for mfg \& trade:inventory/sales (chained 1996 dollars, sa) \\
\hline ivsrmq & $\Delta \mathrm{Ln}$ & 1959:1-2001:7 & ratio for $\mathrm{mfg} \&$ trade:mfg;inventory/sales (1996\$)(s.a.) \\
\hline ivsrwq & $\Delta \mathrm{Ln}$ & 1959:1-2001:7 & ratio for mfg \& trade:wholesaler;inventory/sales(1996\$)(s.a.) \\
\hline ivsrrq & $\Delta \mathrm{Ln}$ & 1959:1-2001:7 & ratio for $\mathrm{mfg} \&$ trade:retail trade;inventory/sales(1996\$)(s.a.) \\
\hline pmi & Lev & 1959:1-2002:12 & purchasing managers' index (sa) \\
\hline pmp & Lev & 1959:1-2002:12 & napm production index (percent) \\
\hline pmno & Lev & 1959:1-2002:12 & napm new orders index (percent) \\
\hline pmdel & Lev & 1959:1-2002:12 & napm vendor deliveries index (percent) \\
\hline pmnv & Lev & 1959:1-2002:12 & napm inventories index (percent) \\
\hline
\end{tabular}




\begin{tabular}{|c|c|c|c|}
\hline pmemp & Lev & 1959:1-2002:12 & napm employment index (percent) \\
\hline pmcp & Lev & 1959:1-2002:12 & napm commodity prices index (percent) \\
\hline mocmq & $\Delta \mathrm{Ln}$ & 1959:1-2002:12 & new orders (net) - consumer goods \& materials, 1996 dollars (bci) \\
\hline msondq & $\Delta \mathrm{Ln}$ & 1959:1-2002:12 & new orders, nondefense capital goods, in 1996 dollars (bci) \\
\hline moq & $\Delta \mathrm{Ln}$ & 1959:1-2001:5 & mfg new orders: all manufacturing industries, total, real (mo/pwfsa) (AC) \\
\hline mdoq & $\Delta \mathrm{Ln}$ & 1959:1-2001:5 & mfg new orders: durable goods industries, total, real (mdo/pwfsa) (AC) \\
\hline muq & $\Delta \mathrm{Ln}$ & 1959:1-2001:5 & mfg unfilled orders: all manufacturing industries, total (mu/pwfsa) (AC) \\
\hline mduq & $\Delta \mathrm{Ln}$ & 1959:1-2001:5 & mfg unfilled orders: durable goods industries, total (mdu/pwfsa) (AC) \\
\hline & & & (D) Interest Rates and Asset Prices \\
\hline fygt10 & $\Delta$ & 1959:1-2002:12 & interest rate:u.s.treasury const maturities,10-yr.(\% per ann,nsa) \\
\hline fclnq & $\Delta \mathrm{Ln}$ & 1959:1-2002:12 & commercial \& industrial loans oustanding in 1996 dollars (bci) \\
\hline fsncom & $\Delta \mathrm{Ln}$ & 1959:1-2002:12 & nyse common stock price index:composite $(12 / 31 / 65=50)$ \\
\hline fsnin & $\Delta \mathrm{Ln}$ & 1966:1-2002:12 & nyse common stock price index:industrial $(12 / 31 / 65=50)$ \\
\hline fsntr & $\Delta \mathrm{Ln}$ & 1966:1-2002:12 & nyse common stock price index:transportation $(12 / 31 / 65=50)$ \\
\hline fsnut & $\Delta \mathrm{Ln}$ & 1966:1-2002:12 & nyse common stock price index:utility $(12 / 31 / 65=50)$ \\
\hline fsnfi & $\Delta \mathrm{Ln}$ & 1966:1-2002:12 & nyse common stock price index:finance $(12 / 31 / 65=50)$ \\
\hline fspcom & $\Delta \mathrm{Ln}$ & 1959:1-2002:12 & s\&p's common stock price index:composite $(1941-43=10)$ \\
\hline fspin & $\Delta \mathrm{Ln}$ & 1959:1-2002:12 & s\&p's common stock price index:industrials $(1941-43=10)$ \\
\hline fsdxp & Lev & 1959:1-2002:12 & s\&p's composite common stock:dividend yield (\% per annum) \\
\hline fspxe & Lev & 1959:1-2002:12 & s\&p's composite common stock:price-earnings ratio $(\%, \mathrm{nsa})$ \\
\hline fyff & $\Delta$ & 1959:1-2002:12 & interest rate:federal funds (effective) (\% per annum,nsa) \\
\hline fygm3 & $\Delta$ & 1959:1-2002:12 & interest rate:u.s.treasury bills,sec mkt,3-mo.(\% per ann,nsa) \\
\hline fygm6 & $\Delta$ & 1959:1-2002:12 & interest rate:u.s.treasury bills,sec mkt,6-mo.(\% per ann,nsa) \\
\hline fygt1 & $\Delta$ & 1959:1-2002:12 & interest rate:u.s.treasury const maturities,1-yr.(\% per ann,nsa) \\
\hline fygt5 & $\Delta$ & 1959:1-2002:12 & interest rate:u.s.treasury const maturities,5-yr.(\% per ann,nsa) \\
\hline $\mathrm{fm} 2 \mathrm{dq}$ & $\Delta \mathrm{Ln}$ & 1959:1-2002:2 & money supply - m2 in 1996 dollars (bci) \\
\hline fyaaac & $\Delta$ & 1959:1-2002:12 & bond yield:moody's aaa corporate (\% per annum) \\
\hline fybaac & $\Delta$ & 1959:1-2002:12 & bond yield:moody's baa corporate (\% per annum) \\
\hline fymcle & $\Delta$ & 1963:1-2002:12 & effective interest rate:conventional home mtge loans closed(\%) \\
\hline sfygm3 & Lev & 1959:1-2002:12 & fygm3-fyff (AC) \\
\hline sfygm6 & Lev & 1959:1-2002:12 & fygm6-fyff (AC) \\
\hline sfygt1 & Lev & 1959:1-2002:12 & fygt1-fyff (AC) \\
\hline sfygt5 & Lev & 1959:1-2002:12 & fygt5-fyff (AC) \\
\hline sfygt10 & Lev & 1959:1-2002:12 & fygt10-fyff (AC) \\
\hline sfyaaac & Lev & 1959:1-2002:12 & fyaaac-fyff $(A C)$ \\
\hline sfybaac & Lev & 1959:1-2002:12 & fybaac-fyff (AC) \\
\hline sfymcle & Lev & 1963:1-2002:12 & fymcle-fyff (AC) \\
\hline exrus & $\Delta \mathrm{Ln}$ & 1959:1-2002:12 & united states; effective exchange rate(merm)(index no.) \\
\hline exrsw & $\Delta \mathrm{Ln}$ & 1959:1-2002:12 & foreign exchange rate:switzerland (swiss franc per u.s.\$) \\
\hline exrjan & $\Delta \mathrm{Ln}$ & 1959:1-2002:12 & foreign exchange rate:japan (yen per u.s.\$) \\
\hline exruk & $\Delta \mathrm{Ln}$ & 1959:1-2002:12 & foreign exchange rate:united kingdom (cents per pound) \\
\hline exrcan & $\Delta \mathrm{Ln}$ & 1959:1-2002:12 & foreign exchange rate:canada (canadian \$ per u.s.\$) \\
\hline \multicolumn{4}{|c|}{ (E) Nominal Prices, Wages, and Money } \\
\hline fm1 & $\Delta \mathrm{Ln}$ & 1959:1-2002:12 & money stock:m1(curr,trav.cks, dem dep,other ck'able dep)(bil\$,sa) \\
\hline fm2 & $\Delta \mathrm{Ln}$ & 1959:1-2002:12 & money stock:m2(m1+o'nite rps,euro $\$, g / p \& b / d$ mmmfs\&sav\&sm time dep(bil\$, \\
\hline fm3 & $\Delta \mathrm{Ln}$ & 1959:1-2002:12 & money stock:m3(m2+lg time dep,term rp's\&inst only mmmfs)(bil\$,sa) \\
\hline fmfba & $\Delta \mathrm{Ln}$ & 1959:1-2002:12 & monetary base, adj for reserve requirement changes(mil\$,sa) \\
\hline fmrra & $\Delta \mathrm{Ln}$ & 1959:1-2002:12 & depository inst reserves:total,adj for reserve req chgs(mil\$,sa) \\
\hline leh & $\Delta \mathrm{Ln}$ & 1964:1-2002:12 & avg hr earnings of prod wkrs:total private nonagric $(\$, s a)$ \\
\hline lehcc & $\Delta \mathrm{Ln}$ & 1959:1-2002:12 & avg hr earnings of constr wkrs:construction $(\$, \mathrm{sa})$ \\
\hline lehm & $\Delta \mathrm{Ln}$ & 1959:1-2002:12 & avg hr earnings of prod wkrs:manufacturing $(\$, s a)$ \\
\hline lehtu & $\Delta \mathrm{Ln}$ & 1964:1-2002:12 & avg hr earnings of nonsupv wkrs:trans \& public util(\$,sa) \\
\hline lehtt & $\Delta \mathrm{Ln}$ & 1964:1-2002:12 & avg hr earnings of prod wkrs:wholesale \& retail trade(sa) \\
\hline lehfr & $\Delta \mathrm{Ln}$ & 1964:1-2002:12 & avg hr earnings of nonsupv wkrs:finance, insur,real est(\$,sa) \\
\hline lehs & $\Delta \mathrm{Ln}$ & 1964:1-2002:12 & avg hr earnings of nonsupv wkrs:services $(\$, \mathrm{sa})$ \\
\hline pwfsa & $\Delta \mathrm{Ln}$ & 1959:1-2002:12 & producer price index:finished goods $(82=100$, sa) \\
\hline pwfcsa & $\Delta \mathrm{Ln}$ & 1959:1-2002:12 & producer price index:finished consumer goods $(82=100, \mathrm{sa})$ \\
\hline pwimsa & $\Delta \mathrm{Ln}$ & 1959:1-2002:12 & producer price index:intermed mat.supplies \& components $(82=100, \mathrm{sa})$ \\
\hline pwcmsa & $\Delta \mathrm{Ln}$ & 1959:1-2002:12 & producer price index:crude materials $(82=100, \mathrm{sa})$ \\
\hline pwfxsa & $\Delta \mathrm{Ln}$ & 1967:1-2002:12 & producer price index:finished goods,excl. foods $(82=100, \mathrm{sa})$ \\
\hline psm99q & $\Delta \mathrm{Ln}$ & 1959:1-2002:12 & index of sensitive materials prices $(1990=100)(b c i-99 a)$ \\
\hline punew & $\Delta \mathrm{Ln}$ & 1959:1-2002:12 & cpi-u:all items $(82-84=100$, sa) \\
\hline pu81 & $\Delta \mathrm{Ln}$ & 1967:1-2002:12 & cpi-u:food \& beverages $(82-84=100$, sa) \\
\hline
\end{tabular}




\begin{tabular}{|c|l|l|l|}
\hline puh & $\Delta \mathrm{Ln}$ & $1967: 1-2002: 12$ & cpi-u:housing $(82-84=100$, sa) \\
\hline pu83 & $\Delta \mathrm{Ln}$ & $1959: 1-2002: 12$ & cpi-u:apparel \& upkeep (82-84=100,sa) \\
\hline pu84 & $\Delta \mathrm{Ln}$ & $1959: 1-2002: 12$ & cpi-u:transportation $(82-84=100, \mathrm{sa})$ \\
\hline pu85 & $\Delta \mathrm{Ln}$ & $1959: 1-2002: 12$ & cpi-u:medical care $(82-84=100, \mathrm{sa})$ \\
\hline pu882 & $\Delta \mathrm{Ln}$ & $1959: 1-2002: 12$ & cpi-u:nondurables $(1982-84=100, \mathrm{sa})$ \\
\hline puc & $\Delta \mathrm{Ln}$ & $1959: 1-2002: 12$ & cpi-u:commodities $(82-84=100$, sa) \\
\hline pucd & $\Delta \mathrm{Ln}$ & $1959: 1-2002: 12$ & cpi-u:durables $(82-84=100, \mathrm{sa})$ \\
\hline pus & $\Delta \mathrm{Ln}$ & $1959: 1-2002: 12$ & cpi-u:services $(82-84=100$, sa) \\
\hline puxf & $\Delta \mathrm{Ln}$ & $1959: 1-2002: 12$ & cpi-u:all items less food $(82-84=100, \mathrm{sa})$ \\
\hline puxhs & $\Delta \mathrm{Ln}$ & $1959: 1-2002: 12$ & cpi-u:all items less shelter $(82-84=100, \mathrm{sa})$ \\
\hline puxm & $\Delta \mathrm{Ln}$ & $1959: 1-2002: 12$ & cpi-u:all items less midical care $(82-84=100$, sa) \\
\hline gmdc & $\Delta \mathrm{Ln}$ & $1959: 1-2002: 12$ & pce,impl pr defl:pce $(1987=100)$ \\
\hline gmdcd & $\Delta \mathrm{Ln}$ & $1959: 1-2002: 12$ & pce,impl pr defl:pce; durables $(1987=100)$ \\
\hline gmdcn & $\Delta \mathrm{Ln}$ & $1959: 1-2002: 12$ & pce,impl pr defl:pce; nondurables $(1996=100)$ \\
\hline gmdcs & $\Delta \mathrm{Ln}$ & $1959: 1-2002: 12$ & pce,impl pr defl:pce; services $(1987=100)$ \\
\hline
\end{tabular}




\section{References}

Ang, A., M. Piazzesi, and M. Wei (2005), "What Does the Yield Curve Tell Us About GDP Growth?” Journal of Econometrics, forthcoming.

Bhansali, R.J. (1996), “Asymptotically Efficient Autogressive Model Selection for Multistep Prediction,” Ann. Inst. Statist. Math., Vol. 48, No. 3, pp. 577-602.

Bhansali, R.J. (1997), “Direct Autoregressive Predictions for Multistep Prediction: Order Selection and Performance Relative to the Plug In Predictors," Statistica Sinca, 7, pp. 425-449.

Bhansali, R.J. (1999), "Parameter Estimation and Model Selection for Multistep Prediction of a Time Series: A Reivew," ch. 6 in Asymptotics, Nonparametrics, and Time Series, S. Ghosh (ed.), Marcel Dekker, $201-225$.

Box, G.E.P. and G.M. Jenkins (1976), Time Series Analysis: Forecasting and Control, $2^{\text {nd }}$ edition. Holden Day, New York.

Brayton, F., J. Roberts and J. Williams (1999), "What's Happened to the Phillips Curve?" manuscript, Feds Working Paper 1999-49, U.S. Federal Reserve Board.

Chevillon, G. and D.F. Hendry (2005), "Non-parametric Direct Multi-step Estimation for Forecasting Economic Processes," International Journal of Forecasting, 21, pp. 201-218.

Clark T.E., McCracken M.W. (2001) “Tests of equal forecast accuracy and encompassing for nested models," Journal of Econometrics 105: 85-100.

Clements, M.P. and D.F. Hendry (1996), "Multi-Step Estimation for Forecasting," Oxford Bulletin of Economics and Statistics 58, pp. 657 - 684.

Cox, D.R. (1961), "Prediction by Exponentially Weighted Moving Averages and Related Methods," JRSS, B23, pp. 414-422.

Findley, D.F. (1983), "On the Use of Multiple Models for Multi-period Forecasting," Porceedings of the Business and Statistics Section, American Statistical Association, pp. 528-531.

Findley, D.F. (1985), "Model Selection for Multi-Step-Ahead Forecasting," in Proceedings of the $7^{\text {th }}$ Symposium on Identification and System Parameter Estimation (H.A. Baker and P.C. Young, eds.). Pergamon, Oxford, 1039 - 1044. 
Ing., C.-K. (2003), “Multistep Prediction in Autoregressive Processes," Econometric Theory, 19, pp. 254-279.

Kang, I.-B. (2003), "Multi-period Forecasting Using Different Models for Different Horizons: An Application to U.S. Economic Time Series Data," International Journal of Forecasting, 19, pp. 387-400.

Kim, Chang-Jin, and Charles R. Nelson (1999), "Has the U.S. Economy Become More Stable? A Bayesian Approach Based on a Markov-Switching Model of the Business Cycle," The Review of Economics and Statistics 81, pp. 608 - 616.

Klein, L.R. (1968), An Essay on the Theory of Economics Prediction, Yrjö Jansen lectures. Helsinki, Finland: Sanomaprint.

Lin, J.-L. and C.W.G. Granger (1994), "Forecasting from Non-linear Models in Practice,: Journal of Forecasting, 13, pp. 1-9.

Liu, S.-I. (1996), “Model Selection for Multiperiod Forecasts,” Biometrika 83, 861 - 873. McConnell, Margaret M, and Gabriel Perez-Quiros (2000), "Output Fluctuations in the United States: What has Changed Since the Early 1980's," American Economic Review 90(5), pp. 1464 - 1476.

Nelson, C.R. and G.W. Schwert (1977), "On Testing the Hypothesis that the Real Rate of Interest is Constant," American Economic Review 67, pp. 478 - 486.

Schorfheide, F. (2005), "VAR Forecasting under Misspecification,” Journal of Econometrics, forthcoming.

Schwert, G.W. (1987), "Effects of Model Misspecification on Tests for Unit Roots in Macroeconomic Data," Journal of Monetary Economics 20, pp. 73 - 103.

Shibata, R. (1980), “Asymptotically Efficient Selection of the Order of the Model for Estimating Parameters of a Linear Process.” Annals of Statistics, Vol. 8, No. 1, pp. 1470-164.

Stock, J.H. (1997), “Cointegration, Long-Run Comovements, and Long-Horizon Forecasting," in D. Kreps and K.F. Wallis (eds), Advances in Econometrics: Proceedings of the Seventh World Congress of the Econometric Society, vol. III. Cambridge: Cambridge University Press, pp. 34-60. 
Stock, J.H. and M.W. Watson (2002a), "Forecasting Using Principal Components from a Large Number of Predictors," Journal of the American Statistical Association, 97, pp. 1167-1179.

Stock, J.H. and M.W. Watson (2002b),, "Macroeconomic Forecasting Using Diffusion Indexes," Journal of Business and Economic Statistics, 20, no. 2, pp. 147-162 .

Tiao, G.C. and D. Xu (1993), "Robustness of MLE for Multi-step Predictions: The Exponential Smoothing Case," Biometrika, 80, pp. 623-641.

Tiao, G.C. and R.S. Tsay (1994), "Some Advances in Non-linear and Adaptive Modelling in Time-series," Journal of Forecasting, 13, pp. 109-131.

Weiss, A.A. (1991), "Multi-step Estimation and Forecasting in Dynamic Models," Journal of Econometrics, 48, pp. 135-149.

West, K.D. (1996), “Asymptotic Inference about Predictive Ability,” Econometrica 64, pp. 1067-1084. 
Table 1

Distributions of relative MSFEs of direct vs. iterated univariate forecasts based on the same lag selection method: All Series

\begin{tabular}{|c|c|c|c|c|c|}
\hline \multirow{2}{*}{ Lag Selection } & \multirow{2}{*}{ Mean/Percentile } & \multicolumn{4}{|c|}{ Forecast Horizon } \\
\hline & & 3 & 6 & 12 & 24 \\
\hline \multirow{6}{*}{$\operatorname{AR}(4)$} & mean & $0.99(<.005)$ & $0.99(<.005)$ & $1.00(<.005)$ & $1.05(0.83)$ \\
\hline & 0.10 & $0.97(<.005)$ & $0.92(<.005)$ & $0.90(<.005)$ & $0.85(<.005)$ \\
\hline & 0.25 & $0.99(<.005)$ & $0.98(<.005)$ & $0.98(<.005)$ & $0.97(0.04)$ \\
\hline & 0.50 & $1.00(0.01)$ & $1.00(0.03)$ & $1.01(0.25)$ & $1.05(>.995)$ \\
\hline & 0.75 & $1.01(0.85)$ & $1.02(0.83)$ & $1.04(0.55)$ & $1.12(>.995)$ \\
\hline & 0.90 & $1.02(0.83)$ & $1.04(0.86)$ & $1.08(0.82)$ & $1.23(0.99)$ \\
\hline \multirow{6}{*}{$\operatorname{AR}(12)$} & mean & $1.01(>.995)$ & $1.01(>.995)$ & $1.03(>.995)$ & $1.10(>.995)$ \\
\hline & 0.10 & $0.98(>.995)$ & $0.97(>.995)$ & $0.95(>.995)$ & $0.93(>.995)$ \\
\hline & 0.25 & $1.00(>.995)$ & $0.99(>.995)$ & $1.00(>.995)$ & $1.02(>.995)$ \\
\hline & 0.50 & $1.00(>.995)$ & $1.01(>.995)$ & $1.03(>.995)$ & $1.09(>.995)$ \\
\hline & 0.75 & $1.01(>.995)$ & $1.02(>.995)$ & $1.06(>.995)$ & $1.17(>.995)$ \\
\hline & 0.90 & $1.02(0.99)$ & $1.05(>.995)$ & $1.11(>.995)$ & $1.29(>.995)$ \\
\hline \multirow{6}{*}{$\mathrm{AR}(\mathrm{BIC})$} & mean & $0.98(<.005)$ & $0.97(<.005)$ & $0.99(0.21)$ & $1.05(0.99)$ \\
\hline & 0.10 & $0.92(<.005)$ & $0.86(<.005)$ & $0.86(0.01)$ & $0.88(0.06)$ \\
\hline & 0.25 & $0.97(<.005)$ & $0.96(<.005)$ & $0.97(0.02)$ & $0.98(0.50)$ \\
\hline & 0.50 & $1.00(<.005)$ & $1.00(0.01)$ & $1.01(0.56)$ & $1.04(>.995)$ \\
\hline & 0.75 & $1.01(0.99)$ & $1.02(0.91)$ & $1.03(0.76)$ & $1.12(>.995)$ \\
\hline & 0.90 & $1.03(>.995)$ & $1.05(>.995)$ & $1.10(>.995)$ & $1.20(0.98)$ \\
\hline \multirow{6}{*}{$\mathrm{AR}(\mathrm{AIC})$} & mean & $1.00(>.995)$ & $1.01(>.995)$ & $1.02(>.995)$ & $1.09(>.995)$ \\
\hline & 0.10 & $0.97(0.51)$ & $0.95(0.99)$ & $0.94(>.995)$ & $0.91(0.97)$ \\
\hline & 0.25 & $0.98(0.08)$ & $0.98(0.90)$ & $0.98(0.97)$ & $1.00(>.995)$ \\
\hline & 0.50 & $1.00(0.22)$ & $1.00(>.995)$ & $1.02(>.995)$ & $1.07(>.995)$ \\
\hline & 0.75 & $1.01(>.995)$ & $1.03(>.995)$ & $1.06(>.995)$ & $1.18(>.995)$ \\
\hline & 0.90 & $1.04(>.995)$ & $1.06(>.995)$ & $1.11(>.995)$ & $1.29(>.995)$ \\
\hline
\end{tabular}

Notes: The first entry in each cell is the indicated summary measure of the distribution of the ratio of the MSFE for the direct forecast to the MSFE of the iterated forecast for the lag selection method listed in the first column and the horizon indicated in the column heading. For each cell, the distribution and summary measure is computed over the 170 series being forecasted. The entry in parentheses is the $p$-value of the test of the hypothesis that the iterated model is efficient, against the alterative that the direct model is more efficient, computed using the parametric bootstrap algorithm described in Section 2 . 
Table 2

Distributions of relative MSFEs of direct vs. iterated univariate forecasts based on the same lag selection method, by category of series

\begin{tabular}{|c|c|c|c|c|c|}
\hline \multirow[t]{2}{*}{ Model } & \multirow[t]{2}{*}{ Mean/Percentile } & \multicolumn{4}{|c|}{ Forecast Horizon } \\
\hline & & 3 & 6 & 12 & 24 \\
\hline \multicolumn{6}{|c|}{ A. Excluding prices, wages, and money } \\
\hline \multirow{6}{*}{$\operatorname{AR}(4)$} & mean & $1.00(0.01)$ & $1.01(0.51)$ & $1.03(0.97)$ & $1.09(>.995)$ \\
\hline & 0.10 & $0.98(<.005)$ & $0.97(<.005)$ & $0.96(0.07)$ & $0.94(0.25)$ \\
\hline & 0.25 & $1.00(0.01)$ & $0.99(0.06)$ & $0.99(0.09)$ & $1.01(>.995)$ \\
\hline & 0.50 & $1.00(0.47)$ & $1.01(0.84)$ & $1.02(0.82)$ & $1.06(>.995)$ \\
\hline & 0.75 & $1.01(0.93)$ & $1.02(0.89)$ & $1.05(0.91)$ & $1.14(>.995)$ \\
\hline & 0.90 & $1.02(0.96)$ & $1.05(0.94)$ & $1.10(0.98)$ & $1.33(>.995)$ \\
\hline \multirow{6}{*}{$\operatorname{AR}(12)$} & mean & $1.01(>.995)$ & $1.01(>.995)$ & $1.03(>.995)$ & $1.11(>.995)$ \\
\hline & 0.10 & $0.99(>.995)$ & $0.97(0.97)$ & $0.96(>.995)$ & $0.93(0.79)$ \\
\hline & 0.25 & $1.00(>.995)$ & $0.99(>.995)$ & $1.00(>.995)$ & $1.03(>.995)$ \\
\hline & 0.50 & $1.00(>.995)$ & $1.01(0.99)$ & $1.03(>.995)$ & $1.11(>.995)$ \\
\hline & 0.75 & $1.01(0.96)$ & $1.02(0.95)$ & $1.06(>.995)$ & $1.18(>.995)$ \\
\hline & 0.90 & $1.02(0.97)$ & $1.04(0.94)$ & $1.12(>.995)$ & 1.31 (>.995) \\
\hline \multirow{6}{*}{$\mathrm{BIC}$} & mean & $1.00(<.005)$ & $1.00(0.01)$ & $1.03(0.94)$ & $1.07(0.99)$ \\
\hline & 0.10 & $0.96(<.005)$ & $0.95(<.005)$ & $0.97(0.30)$ & $0.94(0.28)$ \\
\hline & 0.25 & $0.98(<.005)$ & $0.99(<.005)$ & $0.99(0.14)$ & $1.00(0.98)$ \\
\hline & 0.50 & $1.00(0.04)$ & $1.01(0.22)$ & $1.02(0.86)$ & 1.05 (>.995) \\
\hline & 0.75 & $1.01(0.97)$ & $1.02(0.90)$ & $1.05(0.94)$ & $1.13(>.995)$ \\
\hline & 0.90 & $1.03(>.995)$ & $1.05(0.98)$ & $1.11(>.995)$ & $1.26(0.99)$ \\
\hline \multirow{6}{*}{ AIC } & mean & $1.01(>.995)$ & $1.01(>.995)$ & $1.04(>.995)$ & $1.11(>.995)$ \\
\hline & 0.10 & $0.97(0.08)$ & $0.95(0.17)$ & $0.96(0.88)$ & $0.95(0.83)$ \\
\hline & 0.25 & $0.99(<.005)$ & $0.99(0.77)$ & $0.99(0.78)$ & $1.02(>.995)$ \\
\hline & 0.50 & $1.00(0.20)$ & $1.01(0.98)$ & $1.02(>.995)$ & $1.10(>.995)$ \\
\hline & 0.75 & $1.02(>.995)$ & $1.03(>.995)$ & $1.07(>.995)$ & $1.18(>.995)$ \\
\hline & 0.90 & $1.04(>.995)$ & $1.06(>.995)$ & $1.12(>.995)$ & $1.32(>.995)$ \\
\hline \multicolumn{6}{|c|}{ B. Prices, wages, and money only } \\
\hline \multirow{6}{*}{$\operatorname{AR}(4)$} & mean & $0.96(<.005)$ & $0.90(<.005)$ & $0.87(<.005)$ & $0.90(<.005)$ \\
\hline & 0.10 & $0.90(<.005)$ & $0.68(<.005)$ & $0.57(<.005)$ & $0.64(<.005)$ \\
\hline & 0.25 & $0.95(<.005)$ & $0.87(<.005)$ & $0.78(<.005)$ & $0.77(<.005)$ \\
\hline & 0.50 & $0.98(<.005)$ & $0.95(<.005)$ & $0.92(<.005)$ & $0.95(<.005)$ \\
\hline & 0.75 & $0.99(<.005)$ & $0.98(<.005)$ & $1.00(<.005)$ & $1.04(0.04)$ \\
\hline & 0.90 & $1.01(0.15)$ & $1.01(<.005)$ & $1.04(0.04)$ & $1.10(0.17)$ \\
\hline \multirow{6}{*}{$\operatorname{AR}(12)$} & mean & $1.00(>.995)$ & $1.01(>.995)$ & $1.00(>.995)$ & $1.04(>.995)$ \\
\hline & 0.10 & $0.98(>.995)$ & $0.96(>.995)$ & $0.92(>.995)$ & $0.89(>.995)$ \\
\hline & 0.25 & 0.99 (>.995) & $0.98(>.995)$ & $0.95(>.995)$ & 0.96 (>.995) \\
\hline & 0.50 & $1.00(>.995)$ & $1.01(>.995)$ & $1.01(>.995)$ & $1.04(>.995)$ \\
\hline & 0.75 & $1.01(>.995)$ & $1.03(>.995)$ & $1.04(>.995)$ & $1.13(>.995)$ \\
\hline & 0.90 & $1.02(0.98)$ & $1.06(>.995)$ & $1.07(0.96)$ & $1.20(0.99)$ \\
\hline \multirow{6}{*}{$\mathrm{BIC}$} & mean & $0.93(<.005)$ & $0.86(<.005)$ & $0.86(<.005)$ & $0.96(0.63)$ \\
\hline & 0.10 & $0.74(<.005)$ & $0.56(<.005)$ & $0.56(<.005)$ & $0.68(0.12)$ \\
\hline & 0.25 & $0.91(<.005)$ & $0.81(<.005)$ & $0.72(<.005)$ & $0.79(0.01)$ \\
\hline & 0.50 & $0.95(<.005)$ & $0.88(<.005)$ & $0.91(0.02)$ & $0.97(0.20)$ \\
\hline & 0.75 & $1.00(0.01)$ & $0.98(<.005)$ & $1.00(0.06)$ & 1.09 (>.995) \\
\hline & 0.90 & $1.04(>.995)$ & $1.02(0.82)$ & $1.06(0.87)$ & $1.14(0.92)$ \\
\hline \multirow{6}{*}{ AIC } & mean & $0.98(0.86)$ & $0.98(>.995)$ & $0.96(>.995)$ & $1.00(>.995)$ \\
\hline & 0.10 & $0.92(0.39)$ & $0.87(0.99)$ & $0.85(>.995)$ & $0.81(0.98)$ \\
\hline & 0.25 & $0.95(0.19)$ & $0.96(>.995)$ & $0.89(0.99)$ & $0.90(0.95)$ \\
\hline & 0.50 & $0.99(0.54)$ & $0.99(>.995)$ & $0.99(>.995)$ & $1.00(0.99)$ \\
\hline & 0.75 & $1.01(>.995)$ & $1.01(>.995)$ & $1.03(0.99)$ & $1.07(0.99)$ \\
\hline & 0.90 & $1.02(>.995)$ & $1.06(>.995)$ & $1.06(0.94)$ & $1.18(0.97)$ \\
\hline
\end{tabular}

Notes: See the notes to Table 1. 
Table 3

Relative MSFEs of each univariate forecast method, relative to iterated AR(4), and the fraction of times each forecast method is best

\begin{tabular}{|c|c|c|c|c|c|c|c|c|c|c|c|}
\hline \multirow[b]{2}{*}{$\begin{array}{l}\text { Forecast } \\
\text { Horizon }\end{array}$} & \multirow[b]{2}{*}{$\begin{array}{c}\text { Summary } \\
\text { statistic }\end{array}$} & \multicolumn{5}{|c|}{ Iterated } & \multicolumn{5}{|c|}{ Direct } \\
\hline & & AR(4) & AR(12) & BIC & AIC & sum & AR(4) & AR(12) & $\mathrm{BIC}$ & AIC & sum \\
\hline \multicolumn{12}{|c|}{ A. All series } \\
\hline & mean & 1.00 & 0.99 & 1.01 & 0.99 & & 0.99 & 0.99 & 0.99 & 0.99 & \\
\hline \multirow[t]{3}{*}{3} & median & 1.00 & 1.00 & 1.00 & 1.00 & & 1.00 & 1.00 & 1.00 & 1.00 & \\
\hline & fraction best & 0.15 & 0.22 & 0.21 & 0.12 & 0.70 & 0.06 & 0.14 & 0.06 & 0.08 & 0.33 \\
\hline & mean & 1.00 & 0.97 & 1.00 & 0.97 & & 0.99 & 0.98 & 0.98 & 0.98 & \\
\hline \multirow[t]{3}{*}{6} & median & 1.00 & 1.00 & 1.00 & 1.00 & & 1.00 & 1.01 & 1.01 & 1.00 & \\
\hline & fraction best & 0.15 & 0.25 & 0.15 & 0.19 & 0.75 & 0.05 & 0.14 & 0.05 & 0.06 & 0.31 \\
\hline & mean & 1.00 & 0.98 & 1.00 & 0.97 & & 1.00 & 1.01 & 1.00 & 1.00 & \\
\hline \multirow[t]{3}{*}{12} & median & 1.00 & 1.01 & 1.01 & 1.00 & & 1.01 & 1.03 & 1.02 & 1.02 & \\
\hline & fraction best & 0.25 & 0.23 & 0.14 & 0.17 & 0.79 & 0.07 & 0.09 & 0.05 & 0.05 & 0.25 \\
\hline & mean & 1.00 & 1.01 & 1.00 & 1.00 & & 1.05 & 1.10 & 1.05 & 1.08 & \\
\hline \multirow[t]{2}{*}{24} & median & 1.00 & 1.01 & 1.00 & 1.00 & & 1.05 & 1.09 & 1.04 & 1.08 & \\
\hline & fraction best & 0.22 & 0.22 & 0.16 & 0.21 & 0.81 & 0.09 & 0.05 & 0.05 & 0.04 & 0.22 \\
\hline \multicolumn{12}{|c|}{ B. Excluding Prices, Wages, and Money } \\
\hline & mean & 1.00 & 1.02 & 1.01 & 1.02 & & 1.00 & 1.03 & 1.01 & 1.02 & \\
\hline \multirow[t]{3}{*}{3} & median & 1.00 & 1.02 & 1.00 & 1.01 & & 1.00 & 1.01 & 1.00 & 1.01 & \\
\hline & fraction best & 0.19 & 0.19 & 0.25 & 0.11 & 0.75 & 0.06 & 0.10 & 0.07 & 0.05 & 0.28 \\
\hline & mean & 1.00 & 1.01 & 1.02 & 1.01 & & 1.01 & 1.03 & 1.02 & 1.02 & \\
\hline \multirow[t]{3}{*}{6} & median & 1.00 & 1.02 & 1.00 & 1.00 & & 1.01 & 1.02 & 1.02 & 1.01 & \\
\hline & fraction best & 0.19 & 0.21 & 0.18 & 0.21 & 0.79 & 0.06 & 0.10 & 0.05 & 0.05 & 0.27 \\
\hline & mean & 1.00 & 1.03 & 1.01 & 1.01 & & 1.03 & 1.06 & 1.04 & 1.05 & \\
\hline \multirow[t]{3}{*}{12} & median & 1.00 & 1.02 & 1.01 & 1.00 & & 1.02 & 1.05 & 1.03 & 1.03 & \\
\hline & fraction best & 0.30 & 0.19 & 0.17 & 0.16 & 0.82 & 0.08 & 0.05 & 0.06 & 0.03 & 0.22 \\
\hline & mean & 1.00 & 1.05 & 1.01 & 1.02 & & 1.09 & 1.15 & 1.09 & 1.13 & \\
\hline \multirow[t]{2}{*}{24} & median & 1.00 & 1.01 & 1.00 & 1.00 & & 1.06 & 1.12 & 1.06 & 1.10 & \\
\hline & fraction best & 0.26 & 0.19 & 0.16 & 0.21 & 0.81 & 0.10 & 0.03 & 0.05 & 0.04 & 0.22 \\
\hline \multicolumn{12}{|c|}{ C. Prices, Wages, and Money } \\
\hline & mean & 1.00 & 0.85 & 0.98 & 0.88 & & 0.96 & 0.85 & 0.91 & 0.86 & \\
\hline \multirow[t]{3}{*}{3} & median & 1.00 & 0.87 & 0.99 & 0.89 & & 0.98 & 0.87 & 0.91 & 0.87 & \\
\hline & fraction best & 0.00 & 0.34 & 0.03 & 0.14 & 0.51 & 0.06 & 0.29 & 0.00 & 0.17 & 0.51 \\
\hline & mean & 1.00 & 0.79 & 0.96 & 0.82 & & 0.90 & 0.79 & 0.83 & 0.80 & \\
\hline \multirow[t]{3}{*}{6} & median & 1.00 & 0.81 & 0.98 & 0.83 & & 0.95 & 0.82 & 0.85 & 0.83 & \\
\hline & fraction best & 0.00 & 0.40 & 0.06 & 0.14 & 0.60 & 0.03 & 0.29 & 0.06 & 0.09 & 0.46 \\
\hline & mean & 1.00 & 0.80 & 0.95 & 0.83 & & 0.87 & 0.79 & 0.83 & 0.80 & \\
\hline \multirow[t]{3}{*}{12} & median & 1.00 & 0.84 & 0.99 & 0.85 & & 0.92 & 0.86 & 0.87 & 0.86 & \\
\hline & fraction best & 0.06 & 0.40 & 0.03 & 0.20 & 0.69 & 0.03 & 0.23 & 0.00 & 0.11 & 0.37 \\
\hline & mean & 1.00 & 0.88 & 0.95 & 0.91 & & 0.90 & 0.89 & 0.92 & 0.89 & \\
\hline \multirow[t]{2}{*}{24} & median & 1.00 & 0.88 & 0.99 & 0.90 & & 0.95 & 0.92 & 0.95 & 0.92 & \\
\hline & fraction best & 0.09 & 0.34 & 0.17 & 0.20 & 0.80 & 0.03 & 0.11 & 0.03 & 0.06 & 0.23 \\
\hline \multicolumn{12}{|c|}{ D. Prices, Wages, and Money (I(2) specification) } \\
\hline 3 & mean & 1.00 & 0.85 & 0.91 & 0.85 & & 0.97 & 0.85 & 0.87 & 0.85 & \\
\hline 6 & mean & 1.00 & 0.78 & 0.88 & 0.79 & & 0.91 & 0.79 & 0.80 & 0.78 & \\
\hline 12 & mean & 1.00 & 0.77 & 0.88 & 0.78 & & 0.89 & 0.77 & 0.79 & 0.77 & \\
\hline 24 & mean & 1.00 & 0.79 & 0.89 & 0.80 & & 0.88 & 0.79 & 0.81 & 0.79 & \\
\hline
\end{tabular}

Notes: The entries in the "mean" rows are the mean relative MSFE for the indicated group of series at the indicated horizon, for the column forecasting method, relative to the MSFE for the iterated AR(4) benchmark forecast, where the mean is computed across the 170 series. The entries in the "median" rows are the median of this relative MSFE across the 170 series. The "fraction best" row reports the fraction of the 170 series in which the column forecasting method has the smallest MSFE among the eight possibilities; the sum of these fractions is reported in the "sum" columns respectively for all iterated and for all direct forecasts. The sum of fraction best exceeds 1.0 in some cases because of ties. 
Table 4

$\operatorname{ARIMA}(2,1,1)$ and ARIMA(1,2,1) models for selected price and wage series.

\begin{tabular}{|l|c|c|c|c|c|}
\hline \multirow{2}{*}{ Series } & \multicolumn{2}{|c|}{$\left(\mathbf{1}-\boldsymbol{\phi}_{\mathbf{1}} \mathbf{L}-\boldsymbol{\phi}_{\mathbf{L}} \mathbf{L}^{\mathbf{2}}\right) \Delta \boldsymbol{X}_{\mathbf{t}}=\mathbf{( 1 - \theta \mathbf { L } ) \boldsymbol { \varepsilon } _ { \mathbf { t } }}$} & \multicolumn{2}{c|}{$(\mathbf{1}-\phi \mathbf{L}) \Delta^{\mathbf{2}} \boldsymbol{X}_{\mathbf{t}}=\mathbf{( 1 - \theta \mathbf { L } ) \boldsymbol { \varepsilon } _ { \mathbf { t } }}$} \\
\cline { 2 - 6 } & $\boldsymbol{\phi}_{\mathbf{1}}$ & $\boldsymbol{\phi}_{\mathbf{2}}$ & $\boldsymbol{\theta}$ & $\boldsymbol{\phi}$ & $\boldsymbol{\theta}$ \\
\hline Wages, Construction & 0.57 & 0.41 & 0.93 & -0.42 & 0.93 \\
(lehcc) & $(0.04)$ & $(0.04)$ & $(0.02)$ & $(0.04)$ & $(0.02)$ \\
\hline Wages, Trade and Utilities & 0.78 & 0.21 & 0.91 & -0.21 & 0.92 \\
(lehtu) & $(0.05)$ & $(0.05)$ & $(0.02)$ & $(0.05)$ & $(0.02)$ \\
\hline PPI, Int. Materials & 0.76 & 0.13 & 0.50 & -0.05 & 0.66 \\
(pwimsa) & $(0.09)$ & $(0.07)$ & $(0.09)$ & $(0.06)$ & $(0.05)$ \\
\hline CPI, Food & 1.27 & -0.30 & 0.87 & 0.32 & 0.93 \\
(pu81) & $(0.7)$ & $(0.06)$ & $(0.05)$ & $(0.05)$ & $(0.02)$ \\
\hline CPI, Housing & 1.12 & -0.15 & 0.77 & 0.17 & 0.81 \\
(puh) & $(0.08)$ & $(0.07)$ & $(0.06)$ & $(0.07)$ & $(0.04)$ \\
\hline CPI, Apparel & 1.04 & -0.04 & 0.94 & 0.03 & 0.93 \\
(pu83) & $(0.05)$ & $(0.05)$ & $(0.02)$ & $(0.05)$ & $(0.02)$ \\
\hline CPI, Services & 0.91 & 0.06 & 0.69 & -0.02 & 0.76 \\
(pus) & $(0.07)$ & $(0.06)$ & $(0.05)$ & $(0.06)$ & $(0.04)$ \\
\hline PCE, Durables & 1.04 & -0.06 & 0.82 & 0.08 & 0.85 \\
(gmdcd) & $(0.06)$ & $(0.06)$ & $(0.04)$ & $(0.05)$ & $(0.03)$ \\
\hline
\end{tabular}

Notes: Entries are estimated ARIMA coefficients and standard errors (in parentheses); series mnemonics appear in parentheses in the first column. 
Table 5

Distributions of relative MSFEs of direct vs. iterated bivariate forecasts based on the same lag selection method: All Series

\begin{tabular}{|c|c|c|c|c|c|}
\hline \multirow{2}{*}{ Model } & \multirow{2}{*}{ Mean/Percentile } & \multicolumn{4}{|c|}{ Forecast Horizon } \\
\hline & & 3 & 6 & 12 & 24 \\
\hline \multirow{6}{*}{$\mathrm{AR}(4)$} & mean & 1.00 & 1.00 & 1.02 & 1.09 \\
\hline & 0.10 & 0.96 & 0.90 & 0.85 & 0.82 \\
\hline & 0.25 & 0.99 & 0.97 & 0.96 & 0.96 \\
\hline & 0.50 & 1.00 & 1.01 & 1.02 & 1.06 \\
\hline & 0.75 & 1.02 & 1.04 & 1.08 & 1.19 \\
\hline & 0.90 & 1.03 & 1.07 & 1.16 & 1.37 \\
\hline \multirow{6}{*}{$\operatorname{AR}(12)$} & mean & 1.02 & 1.04 & 1.07 & 1.16 \\
\hline & 0.10 & 0.99 & 0.97 & 0.95 & 0.91 \\
\hline & 0.25 & 1.00 & 1.00 & 1.01 & 1.03 \\
\hline & 0.50 & 1.01 & 1.03 & 1.06 & 1.13 \\
\hline & 0.75 & 1.02 & 1.06 & 1.12 & 1.28 \\
\hline & 0.90 & 1.04 & 1.10 & 1.20 & 1.45 \\
\hline \multirow{6}{*}{$\mathrm{BIC}$} & mean & 0.98 & 0.97 & 0.99 & 1.06 \\
\hline & 0.10 & 0.88 & 0.79 & 0.78 & 0.79 \\
\hline & 0.25 & 0.96 & 0.93 & 0.92 & 0.94 \\
\hline & 0.50 & 1.00 & 1.00 & 1.00 & 1.04 \\
\hline & 0.75 & 1.02 & 1.03 & 1.06 & 1.15 \\
\hline & 0.90 & 1.05 & 1.08 & 1.15 & 1.31 \\
\hline \multirow{6}{*}{$\mathrm{AIC}$} & mean & 1.01 & 1.02 & 1.05 & 1.15 \\
\hline & 0.10 & 0.94 & 0.91 & 0.89 & 0.87 \\
\hline & 0.25 & 0.98 & 0.98 & 0.98 & 1.00 \\
\hline & 0.50 & 1.01 & 1.02 & 1.05 & 1.11 \\
\hline & 0.75 & 1.04 & 1.07 & 1.13 & 1.26 \\
\hline & 0.90 & 1.08 & 1.13 & 1.23 & 1.47 \\
\hline
\end{tabular}

Notes: The entries are based on the 2000 randomly selected pairs of series (4000 forecasts for method and horizon), drawn as described in the text. The "mean" and "median" entries are those summary statistics for the relative MSFEs of the column forecasting method, relative to the iterated VAR(4). See the notes to Table 1. 
Table 6

Relative MSFEs of each bivariate forecast method, relative to iterated VAR(4), and the fraction of times each forecast method is best

\begin{tabular}{|c|c|c|c|c|c|c|c|c|c|c|c|}
\hline \multirow[b]{2}{*}{$\begin{array}{l}\text { Forecast } \\
\text { Horizon }\end{array}$} & \multirow[b]{2}{*}{ Percentile } & \multicolumn{5}{|c|}{ Iterated forecasts } & \multicolumn{5}{|c|}{ Direct forecasts } \\
\hline & & AR(4) & AR(12) & BIC & AIC & sum & AR(4) & $\mathrm{AR}(12)$ & BIC & AIC & sum \\
\hline \multicolumn{12}{|c|}{ A. All Variables } \\
\hline & mean & 1.00 & 1.03 & 1.04 & 1.00 & & 1.00 & 1.04 & 1.01 & .01 & \\
\hline \multirow[t]{3}{*}{3} & median & 1.00 & 1.04 & 1.01 & 1.00 & & 1.00 & 1.05 & 1.01 & .02 & \\
\hline & fraction best & 0.15 & 0.14 & 0.27 & 0.13 & 0.69 & 0.08 & 0.07 & 0.10 & .08 & 0.33 \\
\hline & mean & 1.00 & 1.00 & 1.06 & 0.99 & & 0.99 & 1.03 & 1.01 & .01 & \\
\hline \multirow[t]{3}{*}{6} & median & 1.00 & 1.03 & 1.02 & 1.00 & & 1.01 & 1.05 & 1.01 & .02 & \\
\hline & fraction best & 0.18 & 0.20 & 0.24 & 0.14 & 0.75 & 0.07 & 0.07 & 0.07 & .06 & 0.26 \\
\hline & mean & 1.00 & 1.00 & 1.06 & 0.99 & & 1.01 & 1.07 & 1.03 & .04 & \\
\hline \multirow[t]{3}{*}{12} & median & 1.00 & 1.03 & 1.03 & 1.00 & & 1.02 & 1.09 & 1.03 & .05 & \\
\hline & fraction best & 0.21 & 0.21 & 0.19 & 0.16 & 0.77 & 0.06 & 0.08 & 0.06 & .04 & 0.25 \\
\hline & mean & 1.00 & 1.03 & 1.04 & 0.99 & & 1.09 & 1.19 & 1.09 & .15 & \\
\hline \multirow[t]{2}{*}{24} & median & 1.00 & 1.03 & 1.02 & 1.00 & & 1.06 & 1.15 & 1.07 & .11 & \\
\hline & fraction best & 0.22 & 0.22 & 0.19 & 0.19 & 0.81 & 0.05 & 0.07 & 0.06 & .04 & 0.21 \\
\hline \multicolumn{12}{|c|}{ B. Pairs not including wages, prices, or money } \\
\hline & mean & 1.00 & 1.06 & 1.03 & 1.02 & & 1.01 & 1.08 & 1.02 & .04 & \\
\hline \multirow[t]{3}{*}{3} & median & 1.00 & 1.05 & 1.00 & 1.01 & & 1.01 & 1.06 & 1.01 & .02 & \\
\hline & fraction best & 0.18 & 0.10 & 0.29 & 0.13 & 0.71 & 0.09 & 0.04 & 0.11 & .07 & 0.31 \\
\hline & mean & 1.00 & 1.04 & 1.04 & 1.01 & & 1.02 & 1.08 & 1.03 & .05 & \\
\hline \multirow[t]{3}{*}{6} & median & 1.00 & 1.05 & 1.01 & 1.01 & & 1.01 & 1.07 & 1.02 & .03 & \\
\hline & fraction best & 0.22 & 0.16 & 0.25 & 0.14 & 0.77 & 0.08 & 0.05 & 0.08 & .04 & 0.25 \\
\hline & mean & 1.00 & 1.05 & 1.04 & 1.01 & & 1.05 & 1.12 & 1.05 & .08 & \\
\hline \multirow[t]{3}{*}{12} & median & 1.00 & 1.04 & 1.02 & 1.00 & & 1.03 & 1.11 & 1.03 & .06 & \\
\hline & fraction best & 0.24 & 0.17 & 0.20 & 0.17 & 0.78 & 0.06 & 0.06 & 0.08 & .04 & 0.24 \\
\hline & mean & 1.00 & 1.07 & 1.02 & 1.01 & & 1.12 & 1.23 & 1.10 & .18 & \\
\hline \multirow[t]{2}{*}{24} & median & 1.00 & 1.04 & 1.01 & 1.00 & & 1.08 & 1.18 & 1.07 & .12 & \\
\hline & fraction best & 0.23 & 0.17 & 0.22 & 0.19 & 0.81 & 0.05 & 0.06 & 0.07 & .03 & 0.22 \\
\hline \multicolumn{12}{|c|}{ C. Non price, wage, money variables in pairs that include a price, wage, money variable } \\
\hline & mean & 1.00 & 1.08 & 1.01 & 1.03 & & 1.01 & 1.09 & 1.01 & 1.06 & \\
\hline \multirow[t]{3}{*}{3} & median & 1.00 & 1.07 & 1.00 & 1.02 & & 1.01 & 1.08 & 1.01 & 1.05 & \\
\hline & fraction best & 0.18 & 0.04 & 0.41 & 0.09 & 0.73 & 0.08 & 0.02 & 0.14 & 0.04 & 0.28 \\
\hline & mean & 1.00 & 1.07 & 1.01 & 1.02 & & 1.03 & 1.10 & 1.03 & 1.08 & \\
\hline 6 & median & 1.00 & 1.06 & 1.00 & 1.02 & & 1.02 & 1.09 & 1.02 & 1.06 & \\
\hline & fraction best & 0.22 & 0.07 & 0.41 & 0.13 & 0.82 & 0.06 & 0.02 & 0.06 & 0.04 & 0.18 \\
\hline & mean & 1.00 & 1.08 & 1.02 & 1.03 & & 1.07 & 1.16 & 1.07 & 1.13 & \\
\hline 12 & median & 1.00 & 1.07 & 1.02 & 1.02 & & 1.05 & 1.14 & 1.05 & 1.11 & \\
\hline & fraction best & 0.30 & 0.10 & 0.29 & 0.13 & 0.83 & 0.07 & 0.03 & 0.05 & 0.02 & 0.18 \\
\hline & mean & 1.00 & 1.09 & 1.03 & 1.04 & & 1.16 & 1.32 & 1.16 & 1.28 & \\
\hline 24 & median & 1.00 & 1.07 & 1.02 & 1.02 & & 1.13 & 1.26 & 1.12 & 1.23 & \\
\hline & fraction best & 0.31 & 0.14 & 0.23 & 0.18 & 0.86 & 0.04 & 0.04 & 0.04 & 0.03 & 0.16 \\
\hline & & & D. $P$ & , wag & noney & ariable & & & & & \\
\hline & mean & 1.00 & 0.88 & 1.11 & 0.92 & & 0.97 & 0.88 & 1.01 & 0.89 & \\
\hline 3 & median & 1.00 & 0.89 & 1.05 & 0.94 & & 0.98 & 0.89 & 1.01 & 0.91 & \\
\hline & fraction best & 0.01 & 0.38 & 0.03 & 0.16 & 0.58 & 0.07 & 0.20 & 0.02 & 0.14 & 0.43 \\
\hline & mean & 1.00 & 0.80 & 1.15 & 0.88 & & 0.90 & 0.82 & 0.93 & 0.83 & \\
\hline 6 & median & 1.00 & 0.82 & 1.11 & 0.89 & & 0.92 & 0.84 & 0.95 & 0.84 & \\
\hline & fraction best & 0.01 & 0.47 & 0.03 & 0.14 & 0.64 & 0.04 & 0.17 & 0.04 & 0.12 & 0.37 \\
\hline & mean & 1.00 & 0.79 & 1.15 & 0.87 & & 0.87 & 0.81 & 0.92 & 0.82 & \\
\hline 12 & median & 1.00 & 0.81 & 1.12 & 0.89 & & 0.89 & 0.84 & 0.95 & 0.84 & \\
\hline & fraction best & 0.06 & 0.44 & 0.04 & 0.15 & 0.69 & 0.04 & 0.21 & 0.01 & 0.07 & 0.33 \\
\hline & mean & 1.00 & 0.85 & 1.10 & 0.90 & & 0.91 & 0.93 & 0.97 & 0.92 & \\
\hline 24 & median & 1.00 & 0.83 & 1.08 & 0.91 & & 0.92 & 0.93 & 0.98 & 0.92 & \\
\hline & fraction best & 0.13 & 0.44 & 0.04 & 0.17 & 0.78 & 0.03 & 0.12 & 0.03 & 0.07 & 0.25 \\
\hline
\end{tabular}

Notes: The entries are based on the 2000 randomly selected pairs of series (4000 forecasts for method and horizon), drawn as described in the text. The "mean" and "median" entries are those summary statistics for the relative MSFEs of the column forecasting method, relative to the iterated VAR(4). See the notes to Table 3. 